\title{
Role of neutrophil gelatinase-associated lipocalin in renal cell carcinoma (Review)
}

\author{
KAI CHE ${ }^{1,2}$, WENKAI HAN ${ }^{1,2}$, MINGXIN ZHANG ${ }^{1 *}$ and HAITAO NIU ${ }^{1 *}$ \\ ${ }^{1}$ Department of Urology, The Affiliated Hospital of Qingdao University; ${ }^{2}$ Department of Clinical Medicine, \\ Qingdao University, Qingdao, Shandong 266003, P.R. China
}

Received July 9, 2020; Accepted November 26, 2020

DOI: $10.3892 / \mathrm{ol} .2020 .12409$

\begin{abstract}
Human neutrophil gelatinase-associated lipocalin (NGAL) is a glycoprotein present in a wide variety of tissues and cell types. It exists as a monomer of $25 \mathrm{kDa}$, a homodimer of $45 \mathrm{kDa}$ or a heterodimer of $135 \mathrm{kDa}$ (disulfide bound to latent matrix metalloproteinase-9). NGAL is considered the biochemical gold standard for the early diagnosis of acute kidney injury and has attracted much attention as a diagnostic biomarker. NGAL has controversial (i.e. both beneficial and detrimental) effects on cellular processes associated with tumor development, such as cell proliferation, survival, migration, invasion and drug resistance. Therefore, the present review aimed at clarifying the role of NGAL in renal cell carcinoma (RCC). Relevant studies of NGAL and RCC were searched in PubMed and relevant information about the structure, expression, function and mechanism of NGAL in RCC were summarized. Finally, the following conclusions could be drawn from the literature: i) NGAL can be detected in cancer tissues, serum and urine of patients with RCC; ii) NGAL is not a suitable diagnostic marker for early screening of RCC; iii) NGAL expression may be used to predict the prognosis of patients with RCC; and iv) Further research on NGAL may be helpful to decrease sunitinib resistance and find new treatment strategies for RCC.
\end{abstract}

\section{Contents}

1. Introduction

2. Literature search

Correspondence to: Professor Haitao Niu or Dr Mingxin Zhang, Department of Urology, The Affiliated Hospital of Qingdao University, 16 Jingsu Road, Qingdao, Shandong 266003, P.R. China E-mail:dr.zmx@foxmail.com

E-mail: niuht0532@126.com

${ }^{*}$ Contributed equally

Key words: neutrophil gelatinase-associated lipocalin, renal cell carcinoma, prognosis, diagnosis, biomarker, mechanism
3. Review of NGAL in RCC

4. Discussion

\section{Introduction}

Renal cell carcinoma ( $\mathrm{RCC}$ ) is the most common type of kidney cancer, accounting for $3 \%$ of adult malignancies (1). Although the morbidity of RCC continues to increase in most countries, mortality has remained the same in numerous highly developed countries during the last decades (2). RCC can occur in both men and women, but the ratio of male to female incidence is $\sim 1.5: 1$, and the morbidity was 4.5 times higher in developed countries than in developing countries in 2008 (2). Early detection of RCC is difficult, as this disease lacks early clinical manifestations (3). By the time RCC is diagnosed, 20-30\% of patients are already in the advanced stages of the disease and have developed distant metastasis, which results in a poor prognosis, with a 5-year survival rate of $<10 \%$ (3).

According to the 2016 World Health Organization classification (4), the most common histotypes in RCC are clear cell RCC (ccRCC), papillary RCC (pRCC) and chromophobe RCC (chRCC), which account for 75-80, 10-15 and 6-11\% of RCC cases, respectively (5). The histotype of RCC is an important predictor of tumor prognosis, but it cannot be fully determined by imaging examinations such as abdominal ultrasound or computed tomography. The application of biopsies is controversial since they require experienced cytopathologists and can lead to complications, such as bleeding and tumor spreading along the biopsy route (6). Therefore, a biomarker with good sensitivity and specificity is urgently required, and further studies on the molecular mechanisms of RCC are required to improve the early diagnosis and treatment of RCC.

Neutrophil gelatinase-associated lipocalin (NGAL), also known as lipocalin 2 (LCN2), belongs to the apolipoprotein superfamily. NGAL is a $25-\mathrm{kDa}$ secreted glycoprotein that was first discovered by Kjeldsen et al (7) in 1993 while studying matrix metalloproteinase-9 (MMP-9) in the specific granules of neutrophils. NGAL has received much attention for its biological role as an early warning sign of acute and chronic kidney diseases, and it is regarded as an optional biomarker of renal tubular injury (8). In the last two decades, studies on NGAL in cardiovascular and cerebrovascular diseases, as 
well as diabetes, inflammatory diseases and cancer, have been performed, and as a tumor biomarker, NGAL has attracted much attention $(9,10)$. Previous studies on NGAL have found that the mRNA expression levels of NGAL differ in different types of cancer, and its role may vary $(11,12)$. Additionally, NGAL is expressed in several types of RCC (13) and it may be involved in the development, proliferation, invasion and metastasis of RCC. The purpose of the present review was to discuss the advances in the understanding of the role of NGAL in RCC.

\section{Literature search}

Data and references from relevant articles were identified by searches of the electronic database PubMed (https://pubmed. ncbi.nlm.nih.gov/) using the search terms 'neutrophil gelatinase-associated lipocalin', 'NGAL', 'lipocalin 2', 'Lcn2', 'renal cell carcinoma', 'carcinoma', 'renal cell' and 'RCC'. The last search was run in March 2020. Studies on animal models were excluded. The eligibility criteria included the following: i) Studies on NGAL expression in RCC; ii) Studies that evaluated NGAL as a prognostic or diagnostic marker in $\mathrm{RCC}$; iii) Studies on the functions of NGAL in RCC cell lines in vitro; and iv) Studies identified from relevant references from eligible studies, such as studies on the structure of NGAL or the association between NGAL and breast cancer, colorectal cancer (14), pancreatic cancer (15) or renal cancer. Eligible studies were screened by two authors, and no disagreement existed between authors.

\section{Review of NGAL in RCC}

Structure and biological function of NGAL. The human NGAL gene is a monocistronic gene located on chromosome $9 \mathrm{q} 34$, with a total length of $5,869 \mathrm{bp}$, including a 3,696 bp coding region (7 exons and 6 introns), a 1,695 bp 5'-terminal non-transcribed region and a 178 bp 3'-terminal non-transcribed region (11). The cDNA sequence of the NGAL gene was first identified by cloning in 1994 and consists of a coding region and a 5'-terminal untranslated region. The peptide chain encoded by the NGAL gene contains 198 amino acid residues, including a leading sequence (containing 20 amino acid residues) and the mature peptide (containing 178 amino acid residues) (11). The molecular weight of NGAL is $22.6 \mathrm{kDa}$, which increases to $25 \mathrm{kDa}$ after glycosylation $(16,17)$. NGAL belongs to the apolipoprotein superfamily and has a highly conserved tertiary calyx-shaped structure, composed of 8 anti-parallel $\beta$-strands, a C-terminal $\alpha$-helix and an N-terminal 310-helix (Fig. 1). In humans, NGAL can exist in at least three forms: A monomer of $25 \mathrm{kDa}$, a homodimer of $45 \mathrm{kDa}$ and a heterodimer of $135 \mathrm{kDa}$ (disulfide bound with MMP-9) (18).

Vaidya et al (19) found that under normal physiological conditions, NGAL can be synthesized during a narrow window of granulocyte maturation in the bone marrow, and that NGAL exists in peroxidase-negative neutrophil granules. Additionally, NGAL is expressed at a low level in a variety of cell types, including fat cells, cartilage cells, endometrial carcinoma cells, epithelial cells, endothelial cells, fibroblasts, liver cells, keratinocytes, macrophages, mesangial cells, microglia, lung cells, spleen cells, thymic cells and vascular smooth muscle cells (9). In addition, it is expressed in small amounts in the epithelium of normal human organs, such as lung, kidney, uterus and breast, as well as in the gastrointestinal tract (20). Furthermore, NGAL can be detected in different biological fluids, including blood and urine (21), bile (22), bronchoalveolar lavage fluid (23), hydrothorax (24), ascites (25) and cerebrospinal fluid (26).

The calyx-like structure of NGAL enables it to bind to low molecular weight siderophores to form a NGAL-siderophore-iron complex, which can induce the differentiation of precursor cells into epithelial cells, promote the maturation of primitive renal epithelial cells, scavenge free radicals and decrease the damage caused by oxidative stress to promote the repair of renal injury (27). In addition, NGAL can be coupled with relevant receptors on the cell surface, such as the megalin-cubilin multiscavenger complex found on the brushborder surface of renal tubular epithelial cells, and induce the cell to phagocytose siderophores (28). NGAL can strongly bind to enterobactin, and its iron-binding activity provides a highly effective antibacterial effect, which competitively inhibits the iron intake of bacteria, blocks their access to iron, which is an important nutrient for bacteria, and ultimately inhibits their growth (29). Furthermore, NGAL serves a role in the inflammatory response in vivo, transporting a number of lipophilic molecules that mediate inflammation, such as leukotriene B, platelet activating factor and lipopolysaccharide (30). Another important function of NGAL is to bind to MMP-9 to form heterodimers, preventing the endogenous degradation of MMP-9 and thus maintaining its ability to degrade a large number of structural molecules, such as collagen, fibronectin and laminin (31).

There is evidence indicating that NGAL can be produced by renal tubules and that its concentration is significantly increased after renal injury (13). The diagnostic and prognostic value of NGAL in acute kidney injury (AKI) has been conclusively proven in a series of clinical studies (11). Currently, NGAL is considered the biochemical gold standard for the diagnosis of AKI. When AKI occurs, NGAL concentrations increase in both urine and blood, with the increase in urine being more marked than that in blood (32). It has been confirmed that NGAL levels are positively correlated with the degree of AKI, and NGAL concentrations in urine and blood can be used as an early, sensitive and highly specific biological marker for the diagnosis of AKI (32-34).

Sequence analysis indicated that the cDNA of NGAL and its mouse homolog $24 \mathrm{p} 3$ have $71.3 \%$ homology, and in regards to the coding sequence, the homology is $74.2 \%$ (35). In mice, $24 \mathrm{p} 3$ has been proven to be an oncogene, suggesting that NGAL may also be a novel oncogene in humans (36). Increasing attention has been paid to the role of NGAL in the development and progression of cancer. Some progress has been made in uncovering the association between NGAL and various malignancies, such as breast cancer (37), colorectal cancer (14), pancreatic cancer (15), renal cancer (38) and liver cancer (10).

NGAL expression in RCC tissues. Preliminary studies have revealed that NGAL protein expression in the kidney is very limited, but NGAL protein can be detected in renal proximal tubular epithelial cells (20), whereas studies on NGAL 
Table I. Studies of the gene or protein expression levels of NGAL in RCC tissues.

\begin{tabular}{|c|c|c|c|c|c|c|}
\hline $\begin{array}{l}\text { First } \\
\text { author, year }\end{array}$ & $\begin{array}{l}\text { Type of } \\
\text { cancer }\end{array}$ & $\begin{array}{l}\text { NGAL } \\
\text { measuring method }\end{array}$ & $\begin{array}{l}\text { No. } \\
\text { of patients }\end{array}$ & $\begin{array}{l}\text { No. } \\
\text { of controls }\end{array}$ & Main outcome(s) & Refs. \\
\hline $\begin{array}{l}\text { Friedl } \\
\text { et al, } 1999\end{array}$ & $\mathrm{RCC}$ & IHC & 12 & - & $\begin{array}{l}\text { 10/12 cases with RCC had very } \\
\text { low NGAL expression, while } 2 \text { had } \\
\text { moderate levels. }\end{array}$ & (20) \\
\hline $\begin{array}{l}\text { Barresi } \\
\text { et al, } 2010\end{array}$ & $\begin{array}{l}\text { Renal } \\
\text { tumor }\end{array}$ & IHC & 30 & 30 & $\begin{array}{l}\text { NGAL immunoexpression was found } \\
\text { in } 28 / 30 \text { cases. }\end{array}$ & (13) \\
\hline $\begin{array}{l}\text { Perrin } \\
\text { et al, } 2011\end{array}$ & $\mathrm{ccRCC}$ & IHC & 74 & - & $\begin{array}{l}\text { NGAL was observed in neutrophils } \\
\text { infiltrating ccRCC rather than tumor cells. }\end{array}$ & (39) \\
\hline $\begin{array}{l}\text { Zhang } \\
\text { et al, } 2015\end{array}$ & $\mathrm{RCC}$ & IHC & 189 & - & $\begin{array}{l}\text { NGAL was found in } 14 / 105 \mathrm{ccRCC} \\
\text { and } 57 / 84 \text { pRCC cases. }\end{array}$ & $(38)$ \\
\hline $\begin{array}{l}\text { Rehwald } \\
\text { et al, } 2020\end{array}$ & $\mathrm{RCC}$ & $\begin{array}{l}\text { Immunofluorescence } \\
\text { staining/quantitative } \\
\text { PCR }\end{array}$ & 41 & 41 & $\begin{array}{l}\text { There was a significant increase in NGAL } \\
\text { protein expression in tumor tissues but no } \\
\text { significant changes were observed in } \\
\text { NGAL mRNA expression. }\end{array}$ & $(41)$ \\
\hline $\begin{array}{l}\text { Liu } \\
\text { et al, } 2018\end{array}$ & ccRCC & $\begin{array}{l}\text { TCGA and GEO } \\
\text { database analysis }\end{array}$ & $\begin{array}{l}533 \text { samples in } \\
\text { TCGA; } 11 \\
\text { GEO datasets }\end{array}$ & $\begin{array}{l}\text { Paired } \\
\text { paracancerous } \\
\text { tissues }\end{array}$ & $\begin{array}{l}\text { Lower gene expression levels of NGAL } \\
\text { in ccRCC samples were observed } \\
\text { compared with in paired paracancerous } \\
\text { tissues. }\end{array}$ & $(40)$ \\
\hline
\end{tabular}

NGAL, neutrophil gelatinase-associated lipocalin; RCC, renal cell carcinoma; IHC, immunohistochemistry; ccRCC, clear cell RCC; pRCC, papillary RCC; TCGA, The Cancer Genome Atlas; GEO, Gene Expression Omnibus.

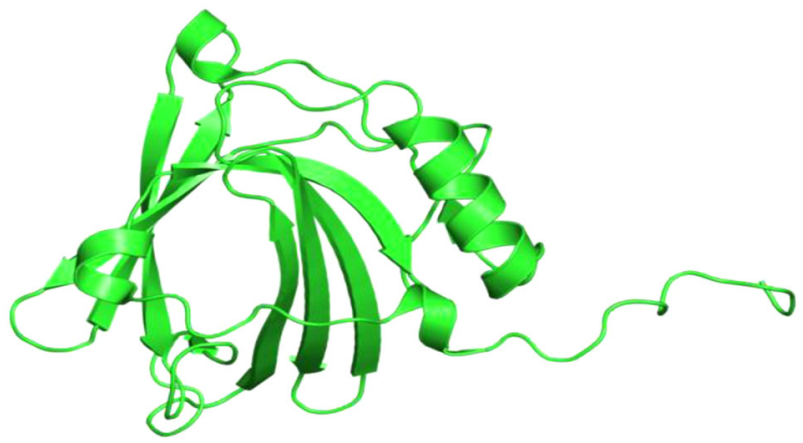

Figure 1. Regularized average nuclear magnetic resonance structure of human neutrophil gelatinase-associated lipocalin from the Protein Data Bank database (ID, 1NGL; http://pdb101.rcsb.org/).

protein expression in RCC have not yielded consistent results (Table I). Notably, according to immunohistochemistry (IHC) staining intensities, Friedl et al (20) found that 10/12 cases of $\mathrm{RCC}$, which is considered to originate from proximal convoluted tubules, had very low NGAL expression, while moderate NGAL expression was found in 2 cases. This was supplemented by further research by Barresi et al (13) in 2010, where NGAL expression was examined by an intensity-distribution (ID) score ( $\geq 4$ was defined as high NGAL expression) in 30 renal tumors. The results revealed that NGAL was weakly expressed in collecting duct epithelial cells and urothelial cells of the renal pelvis, as well as in normal para-carcinoma renal tubules, whereas variable levels of NGAL were detected in 28/30 patients with RCC (1 patient with ccRCC and 1 with a sarcomatoid tumor were excluded, with negative NGAL staining) (13). Moreover, different expression patterns were found in NGAL-positive ccRCC (13). In addition to the staining in the cytoplasm of tumor cells, most ccRCCs had distinct membrane staining, which may be due to the fact that NGAL has not yet been internalized as a result of binding to membrane receptors (13). In another study, Zhang et al (38) found that 57/84 patients with pRCC had positive NGAL expression (ID score $>2$ was identified as high NGAL expression) in the cytoplasm of cancer cells, while only 14/105 patients with ccRCC had cells that expressed NGAL. However, Perrin et al (39) studied 74 RCC samples by IHC and found that NGAL was not expressed in renal tumor cells, but was expressed in neutrophils infiltrating ccRCC tissues (39). The aforementioned studies indicate that there are no unified results on NGAL expression and its subcellular localization in RCC, which may be associated to its differential functions in tumor cells.

The aforementioned studies were conducted by IHC in tumor tissues, but control groups were rarely included. By contrast, Liu et al (40) analyzed 12 ccRCC datasets [1 dataset from The Cancer Genome Atlas (TCGA) and 11 datasets from the Gene Expression Omnibus (GEO) database] and found that, compared with in the paired tissues adjacent to the carcinomas, the gene expression levels of NGAL in the ccRCC group were decreased. Rehwald et al (41) suggested that NGAL gene expression may be inconsistent with NGAL protein expression, since significant increases in NGAL protein expression in ccRCC samples were detected, compared with in corresponding adjacent healthy tissues, but no significant changes in mRNA levels were identified by quantitative PCR 
and immunofluorescence staining when comparing tumor tissues with adjacent healthy tissues (41). Further studies are required to elucidate the differences in gene and protein expression levels of NGAL between RCC and normal tissues.

NGAL as a diagnostic and prognostic marker in RCC. Due to the insidious onset of renal cancer and the lack of early clinical symptoms, a non-invasive screening method is urgently required to improve the early diagnosis and treatment of renal cancer. Therefore, searching for a biomarker with excellent sensitivity and specificity that can be found in the blood or urine of patients with kidney cancer has become a research hotspot. NGAL has attracted considerable attention as a tumor biomarker. Previous studies have revealed that elevated NGAL expression may help predict disease-free survival (DFS) in patients with colorectal cancer (42), but the prognostic utility and diagnostic accuracy of NGAL in RCC remain uncertain (10).

NGAL is expressed in tissues, serum and urine of patients with RCC. Studies on whether NGAL can be used as a diagnostic and prognostic biomarker for RCC are currently underway (Table II). By analyzing NGAL expression in renal tumor tissues, Barresi et al (13) revealed that high NGAL expression is associated with the pRCC and chRCC histotypes and is significantly associated with the Fuhrman grading of ccRCC and pRCC (43). There was no significant association between NGAL expression and patient age, sex, serum iron levels, tumor size or tumor stage (13). Zhang et al (38) studied the association between NGAL expression and the prognosis of patients with ccRCC and pRCC, and found that high NGAL expression was associated with decreased overall survival (OS) and DFS in patients with pRCC, but it was not associated with OS and DFS in patients with ccRCC. Survival analysis of 533 patients with ccRCC in the TCGA database revealed that high NGAL expression was associated with a decreased survival rate compared with low NGAL expression $(40,41)$. Although high NGAL expression in tumor tissues is associated with the type of tissue, it is impossible to distinguish different histotypes of RCC based on NGAL expression, but it may help to predict the OS and DFS of patients with RCC.

With current technological limitations, the only clinical test of NGAL in biofluids is used to diagnose AKI, as its levels are associated with the severity of kidney injury in adults and neonates (44-46). Whether the NGAL level in biofluids can be used as a diagnostic and prognostic indicator for patients with kidney cancer is under investigation. Previous studies have revealed that elevated levels of urinary and serum NGAL in patients with RCC are independent of histotype, stage and grade $(47,48)$. NGAL was not a sensitive or a specific urinary biomarker for RCC. Although the concentration of NGAL in urine (uNGAL) in 67 patients with renal cancer undergoing nephrectomy ( $0.52 \mathrm{ng} / \mathrm{mg}$ creatinine; range, $0.28-0.73 \mathrm{ng} / \mathrm{mg}$ creatinine) was statistically different from 55 patients undergoing non-nephrectomy (typically orthopedic) surgery $(0.15 \mathrm{ng} / \mathrm{mg}$ creatinine; range, $0.04-0.31 \mathrm{ng} / \mathrm{mg}$ creatinine $)$, only 8 patients had an uNGAL level with no overlap with the control group before nephrectomy. In addition, there was no significant association between UNGAL and tumor size with stage (47). In another study, Saint et al (49) revealed that high NGAL expression was associated with increased tumor stage and Furhman grade in patients with renal cancer and that high
uNGAL excretion was associated with poor progression-free survival (PFS) and disease-specific survival (DSS) in patients with ccRCC. Although uNGAL may not be suitable as a specific biomarker for RCC $(6,47,48)$, elevated levels of NGAL in serum (sNGAL) are associated with decreased PFS in patients with RCC $(39,50)$. Although high concentrations of NGAL in biofluids do not help to diagnose RCC, these are negatively associated with the prognosis of patients with RCC. Measuring the levels of NGAL may be helpful for selecting the appropriate treatment for patients with advanced RCC. Patients with advanced RCC were treated with sunitinib, a small molecule tyrosine kinase inhibitor with targets including vascular endothelial growth factor, platelet-derived growth factor receptor- $\alpha$ and $\beta$, and stem cell factor receptor, which has become one of the two main first-line treatments available for RCC (51). With $177 \mathrm{ng} / \mathrm{ml}$ being the cut-off value, low sNGAL predicted a longer PFS than high sNGAL and was superior to the best available clinical factor, the Motzer score (50). Furthermore, the expression levels of NGAL in RCC cells can be used as a predictive biomarker for sensitivity to sunitinib before targeted therapy (51).

Mechanism of NGAL in RCC. Since the synthesis of NGAL is induced by cancer-promoting factors, it is considered to serve a key role in the development and progression of human tumors (52). Previous studies have highlighted how NGAL is involved in the development, proliferation and invasion of cancer. In fact, elevated levels of this protein have been detected in the serum or urine of patients with different types of tumor, such as colon, breast, brain, thyroid, esophageal and bladder cancer (10). However, depending on the type of tumor, NGAL may have distinct roles in promoting or preventing cancer (10). Bolignano et al (52) observed that when NGAL acts as an intracellular iron carrier and protects MMP-9 from degradation, it has a significant cancer-promoting effect, as identified in human tumors including breast, stomach, esophageal, rectal, thyroid and brain tumors. By contrast, Zhang et al (53) reported that NGAL inhibited the production of the cancer-promoting factor hypoxia-inducible factor 1 (HIF-1), phosphorylation of focal adhesion kinase and synthesis of vascular endothelial growth factor (VEGF), and had an antitumor and anti-metastatic effect on colon, ovarian and pancreatic tumors.

In a recent study of RCC, Rehwald et al (41) revealed that iron-loaded NGAL had tumor-promoting effects in RCC cell lines, while iron-free NGAL had the opposite effect. In another study, Yu et al (51) reported that NGAL promoted RCC cell proliferation by enhancing the activation of the Ras-GTP, Erk1/2 and STAT1a signaling pathways. Currently, a number of hypotheses have been proposed regarding the possibility of NGAL promoting tumor progression, most of which involve the binding of NGAL to MMP-9 or the involvement of NGAL in iron uptake $(41,54)$. Based on the aforementioned literature, it is likely that NGAL may serve a role in the development, progression, invasion and metastasis of RCC through the aforementioned pathways (Fig. 2).

MMP-9 is a gelatinase that degrades a wide range of substrates, including collagen, fibronectin and laminin, to promote tumor invasion and metastasis (11). In addition, numerous experimental evidence supports that MMP-9 is 


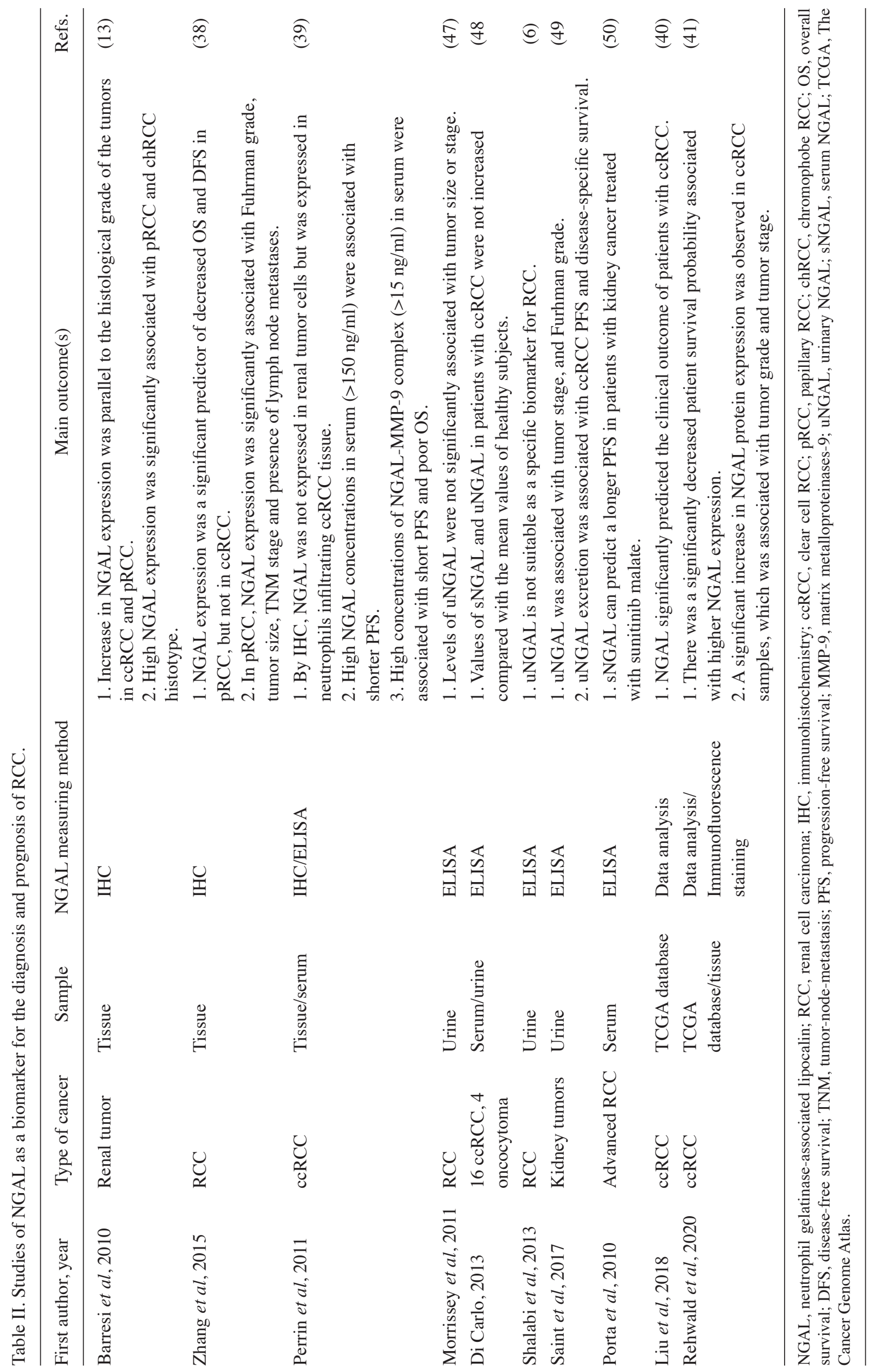




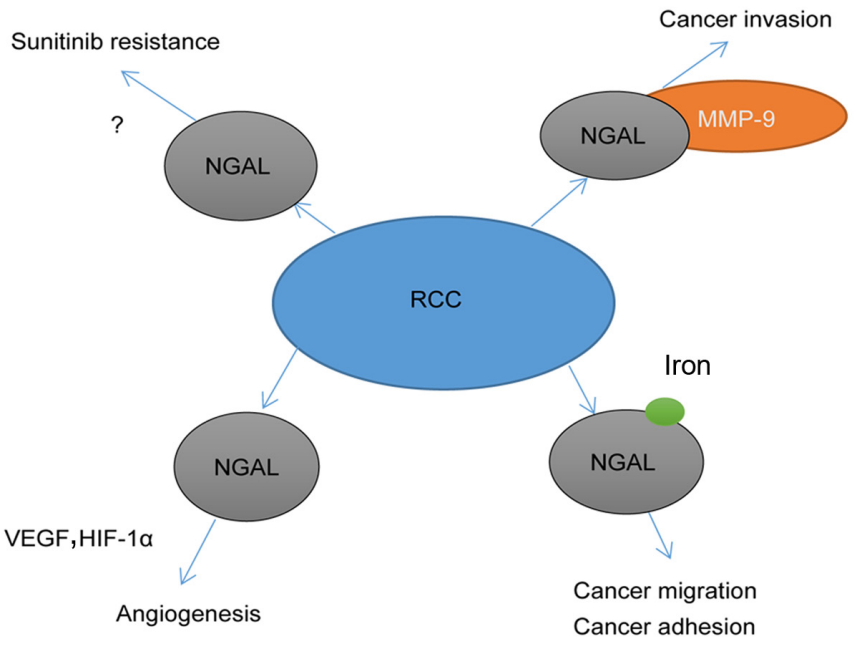

Figure 2. Potential biological mechanisms of NGAL in RCC. NGAL, neutrophil gelatinase-associated lipocalin; RCC, renal cell carcinoma; MMP-9, matrix metalloproteinases-9; VEGF, vascular endothelial growth factor; HIF-1 $\alpha$, hypoxia-inducible factor $1 \alpha$.

directly involved in angiogenesis $(55,56)$. NGAL can regulate the activity of MMP-9 by binding to pro-MMP-9 and forming a ternary complex to decrease the degradation of MMP-9 (57). In a ccRCC cohort, high levels of the MMP-9/NGAL complex in patient serum were associated with shorter PFS and lower OS than low levels of the complex (39), suggesting that NGAL may promote invasion and metastasis of cancer by binding with MMP-9 in ccRCC.

Due to the high proliferation rate of tumor cells, large amounts of iron are required to maintain their enhanced metabolic conversion (58). The unique iron transport capacity of NGAL is crucial to its tumor-promoting ability. Several studies have explored the mechanisms by which NGAL promotes human cancer, emphasizing how NGAL promotes iron uptake in the extracellular space of malignant cells to sustain tumor cell proliferation. In breast cancer, for example, blocking the release of iron-loaded NGAL by inhibiting tumor-associated macrophages significantly decreased tumor growth (59). Rehwald et al (41) found a significant increase in NGAL expression, especially iron-loaded NGAL, in tumor tissues of patients with RCC compared with that of adjacent healthy tissues. Iron-loaded NGAL accounts for $2 \%$ of NGAL in healthy tissues and $20 \%$ of NGAL in tumor tissues (41). Similarly, in a study with RCC cell lines, compared with iron-free NGAL and mutated NGAL (which was unable to bind to iron), iron-loaded NGAL significantly enhanced the migration and adhesion of RCC cells (786-O, RCC4, A498 and CAKI1), but cell proliferation remained unchanged after stimulation with the aforementioned three molecules (41). These results indicate that although iron-loaded NGAL cannot promote the proliferation of RCC cells, it may be able to promote the invasion and metastasis of RCC by enhancing the migration and adhesion of RCC cells.

In addition to the aforementioned hypotheses, NGAL is considered to be a cytokine that promotes angiogenesis in tumors (60). Overexpression of NGAL in a ductal adenocarcinoma cell line (PANC1) characterized by low endogenous NGAL expression significantly enhanced tumor invasion, adhesion and growth, and promoted VEGF and HIF-1 $\alpha$ expression, which serve an important role in cancer angiogenesis (11). However, Ferreira et al (61) argued that in the presence of ferrous iron, NGAL is involved in iron absorption, which inhibits HIF-1 $\alpha$. In addition, NGAL has similar features to $\mathrm{NF}-\kappa \mathrm{B}$, such as the potential to protect thyroid cancer cells from apoptosis induced by growth factor deprivation (11). However, to the best of our knowledge, the aforementioned findings have not been verified in RCC.

\section{Discussion}

To the best of our knowledge, the present review was the first to evaluate the possible role of NGAL in RCC. Previous studies on NGAL have found that NGAL expression varies among different types of cancer, and its role may be different. In breast cancer (62) or thyroid cancer (63), overexpression of NGAL enhances cancer cell motility and invasiveness, while in pancreatic cancer (64), overexpression of NGAL decreases tumor volume, along with local and distant metastasis. Therefore, the present review aimed to address the role of NGAL in RCC.

NGAL can be detected in most RCCs. Studies of the TCGA and GEO databases revealed that NGAL gene expression in RCC tissues was decreased compared with that in normal tissues $(40,41)$, while RCC samples had variable levels of NGAL protein expression. There was no significant association between NGAL expression and patient age, sex, serum iron level, tumor type, tumor size or tumor stage (13), but it may be useful for predicting patient prognosis. In addition, different studies have not obtained consistent results on NGAL expression in RCC and on whether NGAL is located in the cytoplasm or the cell membrane, whether it is secreted by neutrophils, RCC infiltrating cells or cancer cells, and why the gene and protein expression levels of NGAL are inconsistent, which requires further investigation.

NGAL has attracted considerable attention as a tumor biomarker. Whether NGAL expression in biological fluids can be used as a diagnostic and prognostic biomarker in patients with RCC is currently being investigated. Based on the existing studies, although uNGAL may be associated with tumor stage and grade, as well as PFS and DSS in patients with RCC (49), it may not be suitable as a specific diagnostic biomarker for RCC. By contrast, sNGAL may be more promising. Increased sNGAL was associated with decreased PFS in patients with RCC $(39,50)$. Additionally, sNGAL may be used to select patients with RCC who are suitable for sunitinib treatment (51). However, whether UNGAL or sNGAL may be utilized for the diagnosis and prognosis of RCC remain controversial, as there are numerous problems to be solved. For example, no studies have confirmed that UNGAL or SNGAL originates from RCC tissues. In addition, the cut-off value for NGAL concentration in serum or urine used to distinguish between healthy individuals and patients with RCC is not always clear. In the future, the detection of NGAL in blood and urine of patients with RCC should be further studied.

Research on the role of NGAL is helpful for the treatment of patients with RCC. NGAL is likely to promote invasion and metastasis of RCC cells by binding to MMP-9, and it may also promote cancer development by binding to iron or inducing angiogenesis via VEGF and HIF-1 (11). Experiments 
in vitro have proven that iron-loaded NGAL can contribute to the migration and adhesion of RCC cells, but it has no effect on the proliferation of tumor cells (41). Blocking the binding of NGAL to MMP-9 or iron may inhibit the invasion and metastasis of RCC. Cancers characterized by high NGAL expression, such as chRCC and pRCC, may be better candidates for treatment with anticancer agents that function as iron chelators than cancers with low NGAL expression (65). In addition, a previous study has revealed that patients with RCC develop resistance to sunitinib by upregulating NGAL expression to activate the angiogenesis pathway (51). Therefore, we speculate that the inhibition of NGAL may decrease resistance to sunitinib.

In conclusion, although NGAL in biofluids cannot be used as a diagnostic marker for early screening of RCC, NGAL expression in serum, urine or tumor tissues may be used to predict the prognosis of patients with RCC. The prognostic value of NGAL in patients with RCC requires to be further investigated. Further research on NGAL may be helpful to decrease sunitinib resistance and identify new treatment strategies for RCC.

\section{Acknowledgements}

Not applicable.

\section{Funding}

No funding was received.

\section{Availability of data and materials}

Not applicable.

\section{Authors' contributions}

MZ designed the study, and $\mathrm{KC}$ drafted the manuscript and revised the manuscript together with $\mathrm{WH}$. HN reviewed the manuscript and gave final approval of the version to be published. All authors read and approved the final version of the manuscript.

\section{Ethics approval and consent to participate}

Not applicable.

\section{Patient consent for publication}

Not applicable.

\section{Competing interests}

The authors declare that they have no competing interests.

\section{References}

1. Linehan WM, Srinivasan R and Schmidt LS: The genetic basis of kidney cancer: A metabolic disease. Nat Rev Urol 7: 277-285, 2010.

2. Znaor A, Lortet-Tieulent J, Laversanne M, Jemal A and Bray F: International variations and trends in renal cell carcinoma incidence and mortality. Eur Urol 67: 519-530, 2015
3. Ljungberg B, Bensalah K, Canfield S, Dabestani S, Hofmann F, Hora M, Kuczyk MA, Lam T, Marconi L and Merseburger AS: EAU guidelines on renal cell carcinoma: 2014 update. Eur Urol 67: 913-924, 2015

4. Moch H, Cubilla AL, Humphrey PA, Reuter VE and Ulbright TM: The 2016 WHO classification of tumours of the urinary system and male genital organs-part A: Renal, penile, and testicular tumours. Eur Urol 70: 93-105, 2016.

5. Signoretti S, Chen YB, Reuter VE and Flaifel A: Renal cell carcinoma in the era of precision medicine: From molecular pathology to tissue-based biomarkers. J Clin Oncol 36: 3553-3559, 2018.

6. Shalabi A, Abassi Z, Awad H, Halachmi S, Moskovitz B, Kluger Y and Nativ O: Urinary NGAL and KIM-1: Potential association with histopathologic features in patients with renal cell carcinoma. World J Urol 31: 1541-1545, 2013.

7. Kjeldsen LS, Johnsen AH, Sengeløv H and Borregaard N: Isolation and primary structure of NGAL, a novel protein associated with human neutrophil gelatinase. J Biol Chem 268: 10425-10432, 1993.

8. Castillo-Rodriguez E, Fernandez-Prado R, Martin-Cleary C, Pizarro-Sánchez MS, Sanchez-Niño MD, Sanz AB, Fernandez-Fernandez B and Ortiz A: Kidney injury marker 1 and neutrophil gelatinase-associated lipocalin in chronic kidney disease. Nephron 136: 263-267, 2017.

9. Makris K, Rizos D, Kafkas N and Haliassos A: Neurophil gelatinase-associated lipocalin as a new biomarker in laboratory medicine. Clin Chem Lab Med 50: 1519-1532, 2012.

10. Roli L, Pecoraro V and Trenti T: Can NGAL be employed as prognostic and diagnostic biomarker in human cancers? A systematic review of current evidence. Int J Biol Markers 32: e53-e61, 2017.

11. Lippi G, Meschi T, Nouvenne A, Mattiuzzi C and Borghi L: Neutrophil gelatinase-associated lipocalin in cancer. Adv Clin Chem 64: 179-219, 2014

12. Monisha J, Roy NK, Padmavathi G, Banik K, Bordoloi D, Khwairakpam AD, Arfuso F, Chinnathambi A, Alahmadi TA, Alharbi SA, et al: NGAL is downregulated in oral squamous cell carcinoma and leads to increased survival, proliferation, migration and chemoresistance. Cancers (Basel) 10: 228, 2018.

13. Barresi V, Ieni A, Bolignano D, Magno C, Buemi M and Barresi G: Neutrophil gelatinase-associated lipocalin immunoexpression in renal tumors: Correlation with histotype and histological grade. Oncol Rep 24: 305-310, 2010.

14. Marti J and Fuster J: Prognostic value of serum neutrophil gelatinase-associated lipocalin in metastatic and non-metastatic colorectal cancer: Reply. World J Surg 37: 2729, 2013.

15. Xu B, Jin DY, Lou WH and Wang DS: Lipocalin-2 is associated with a good prognosis and reversing epithelial-to-mesenchymal transition in pancreatic cancer. World J Surg 37: 1892-1900, 2013.

16. Bundgaard JR, Sengel $\varnothing \mathrm{v}$ H, Borregaard N and Kjeldsen L: Molecular cloning and expression of a cDNA encoding NGAL: A lipocalin expressed in human neutrophils. Biochem Biophys Res Commun 202: 1468-1475, 1994.

17. Cowland JB and Borregaard N: Molecular characterization and pattern of tissue expression of the gene for neutrophil gelatinase-associated lipocalin from humans. Genomics 45: 17-23, 1997

18. Chakraborty S, Kaur S, Guha S and Batra SK: The multifaceted roles of neutrophil gelatinase associated lipocalin (NGAL) in inflammation and cancer. Biochim Biophys Acta 1826: 129-169, 2012.

19. Vaidya VS, Ferguson MA and Bonventre JV: Biomarkers of acute kidney injury. Ann Rev Pharmacol Toxicol 48: 463-493, 2008.

20. Friedl A, Stoesz SP, Buckley P and Gould MN: Neutrophil gelatinase-associated lipocalin in normal and neoplastic human tissues. Cell type-specific pattern of expression. Histochem J 31: 433-441, 1999

21. Lippi G and Plebani M: Neutrophil gelatinase-associated lipocalin (NGAL): The laboratory perspective. Clin Chem Lab Med 0: 1-5, 2012.

22. Zabron AA, Horneffer-van der Sluis VM, Wadsworth CA, Laird F, Gierula M, Thillainayagam AV, Vlavianos P, Westaby D, Taylor-Robinson SD, Edwards RJ and Khan SA: Elevated levels of neutrophil gelatinase-associated lipocalin in bile from patients with malignant pancreatobiliary disease. Am J Gastroenterol 106: 1711-1717, 2011. 
23. Capoluongo E, Vento G, Lulli P, Di Stasio E, Porzio S, Vendettuoli V, Tana M, Tirone C, Romagnoli C, Zuppi C and Ameglio F: Epithelial lining fluid neutrophil-gelatinase-associated lipocalin levels in premature newborns with bronchopulmonary dysplasia and patency of ductus arteriosus. Int J Immunopathol Pharmacol 21: 173-179, 2008.

24. Kotyza J, Bunatova K, Pesek M and Puzman P: Pleural injury and pleurisy-induced progelatinase B/proMMP-9 is associated with markers of neutrophil degranulation. Scand J Clin Lab Invest 66: 487-496, 2006.

25. Lippi G, Caleffi A, Pipitone S, Elia G, Ngah A, Aloe R, Avanzini P and Ferrari C: Assessment of neutrophil gelatinase-associated lipocalin and lactate dehydrogenase in peritoneal fluids for the screening of bacterial peritonitis. Clin Chim Acta 418: 59-62, 2013.

26. Lippi G, Avanzini P, Calzetti C, Caleffi A, Pipitone S, Musa R, Aloe R and Ferrari C: The role of neutrophil gelatinase-associated lipocalin (NGAL) in cerebrospinal fluids for screening of acute bacterial meningitis. Clin Lab 60: 377-381, 2014.

27. Schmidt-Otta KM, Mori K, Kalandadzea A, Li JY, Paragasa N, Nicholas T, Devarajan P and Barasch J: Neutrophil gelatinase-associated lipocalin-mediated iron traffic in kidney epithelia. Curr Opin Nephrol Hypertens 15: 442-449, 2006.

28. Soni SS, Cruz D, Bobek I, Chionh CY, Nalesso F, Lentini P, de Cal M, Corradi V, Virzi G and Ronco C: NGAL: A biomarker of acute kidney injury and other systemic conditions. Int Urol Nephrol 42: 141-150, 2010.

29. Gwira JA, Wei F, Ishibe S, Ueland JM, Barasch J and Cantley LG: Expression of neutrophil gelatinase-associated lipocalin regulates epithelial morphogenesis in vitro. J Biol Chem 280 7875-7882, 2005.

30. Goetz DH, Willie ST, Armen RS, Bratt T, Borregaard N and Strong RK: Ligand preference inferred from the structure of neutrophil gelatinase associated lipocalin. Biochemistry 39: 1935-1941, 2000.

31. Yan L, Borregaard N, Kjeldsen L and Moses MA: The high molecular weight urinary matrix metalloproteinase (MMP) activity is a complex of gelatinase B/MMP-9 and neutrophil gelatinase-associated lipocalin (NGAL). Modulation of MMP-9 activity by NGAL. J Biol Chem 276: 37258-37265, 2001.

32. Antonucci E, Lippi G, Ticinesi A, Pigna F, Guida L, Morelli I, Nouvenne A, Borghi L and Meschi T: Neutrophil gelatinase-associated lipocalin (NGAL): A promising biomarker for the early diagnosis of acute kidney injury (AKI). Acta Biomed 85 : 289-294, 2014

33. Rosner MH: Urinary biomarkers for the detection of renal injury. Adv Clin Chem 49: 73-97, 2009.

34. Cervellin G and di Somma S: Neutrophil gelatinase-associated lipocalin (NGAL): The clinician's perspective. Clin Chem Lab Med 50: 1489-1493, 2012.

35. Kjeldsen L, Cowland JB and Borregaard N: Human neutrophil gelatinase-associated lipocalin and homologous proteins in rat and mouse. Biochim Biophys Acta 1482: 272-283, 2000.

36. Garay-Rojas E, Harper M, Hraba-Renevey S and Kress M: An apparent autocrine mechanism amplifies the dexamethasone- and retinoic acid-induced expression of mouse lipocalin-encoding gene 24p3. Gene 170: 173-180, 1996.

37. Wenners AS, Mehta K, Loibl S, Park H, Mueller B, Arnold N, Hamann S Weimer J, Ataseven B, Darb-Esfahani S, et al: Neutrophil gelatinase-associated lipocalin (NGAL) predicts response to neoadjuvant chemotherapy and clinical outcome in primary human breast cancer. PLoS One 7: e45826, 2012.

38. Zhang M, Zhao X, Deng Y, Tang B, Sun Q, Zhang Q, Chen W, Yao D, Yang J, Cao L and Guo H: Neutrophil gelatinase associated lipocalin is an independent predictor of poor prognosis in cases of papillary renal cell carcinoma. J Urol 194: 647-652, 2015.

39. Perrin C, Patard JJ, Jouan F, Collet N, Théoleyre S, Edeline J, ZerroukiS,Laguerre B, Bellaud-Roturaud MA, Rioux-Leclercq N and Vigneau C: The neutrophil gelatinase-associated lipocalin, or LCN 2, marker of aggressiveness in clear cell renal cell carcinoma. Prog Urol 21: 851-858, 2011.

40. Liu F, Li N, Yang W, Wang R, Yu J and Wang X: The expression analysis of NGAL and NGALR in clear cell renal cell carcinoma. Gene 676: 269-278, 2018.

41. Rehwald C, Schnetz M, Urbschat A, Mertens C, Meier JK, Bauer R, Baer P, Winslow S, Roos FC and Zwicker K: The iron load of lipocalin-2 (LCN-2) defines its pro-tumour function in clear-cell renal cell carcinoma. Br J Cancer 122: 421-433, 2020.
42. Barresi V, Reggiani-Bonetti L, Di Gregorio C, Vitarelli E, De Leon MP and Barresi G: Neutrophil gelatinase-associated lipocalin (NGAL) and matrix metalloproteinase-9 (MMP-9) prognostic value in stage I colorectal carcinoma. Pathol Res Pract 207: 479-486, 2011.

43. Lang H, Lindner V, de Fromont M, Molinié V, Letourneux H, Meyer N, Martin M and Jacqmin D: Multicenter determination of optimal interobserver agreement using the fuhrman grading system for renal cell carcinoma: Assessment of 241 patients with $>$ 15-year follow-up. Cancer 103: 625-629, 2005.

44. Haase-Fielitz A,Haase M and Devarajan P: Neutrophil gelatinase-associated lipocalin as a biomarker of acute kidney injury: A critical evaluation of current status. Ann Clin Biochem 51: 335-351, 2014.

45. Devarajan P: Neutrophil gelatinase-associated lipocalin (NGAL): A new marker of kidney disease. Scand J Clin Lab Invest Suppl 241: 89-94, 2008.

46. Candido S, Abrams SL, Steelman LS, Lertpiriyapong K, Fitzgerald TL, Martelli AM, Cocco L, Montalto G, Cervello M, Polesel J, et al: Roles of NGAL and MMP-9 in the tumor microenvironment and sensitivity to targeted therapy. Biochim Biophys Acta 1863: 438-448, 2016.

47. Morrissey JJ, London AN, Lambert MC and Kharasch ED: Sensitivity and specificity of urinary neutrophil gelatinase-associated lipocalin and kidney injury molecule-1 for the diagnosis of renal cell carcinoma. Am J Nephrol 34: 391-398, 2011.

48. DI Carlo A: Evaluation of neutrophil gelatinase-associated lipocalin (NGAL), matrix metalloproteinase-9 (MMP-9) and their complex MMP-9/NGAL in sera and urine of patients with kidney tumors. Oncol Lett 5: 1677-1681, 2013.

49. Saint F, Rose-Robert F, Herpe YE, de Sousa P, Sevestre H, Choukhroun G and Amant C: ARCHITECT ${ }^{\circledR}$ urine-neutrophil gelatinase-associated lipocalin (uNGAL) essay: New prognostic marker for clear cell renal cell carcinoma (ccRCC). Annals Oncol 28: vii9, 2017

50. Porta C, Paglino C, De Amici M, Quaglini S, Sacchi L, Imarisio I and Canipari C: Predictive value of baseline serum vascular endothelial growth factor and neutrophil gelatinase-associated lipocalin in advanced kidney cancer patients receiving sunitinib. Kidney Int 77: 809-815, 2010.

51. Yu DS, Wu CL, Ping SY, Huang YL and Shen KH: NGAL can alternately mediate sunitinib resistance in renal cell carcinoma. J Urol 192: 559-566, 2014.

52. Bolignano D, Donato V, Lacquaniti A, Fazio MR, Bono C, Coppolino G and Buemi M: Neutrophil gelatinase-associated lipocalin (NGAL) in human neoplasias: A new protein enters the scene. Cancer Lett 288: 10-16, 2010.

53. Zhang XF, Zhang Y, Zhang XH, Zhou SM, Yang GG, Wang OC, Guo GL, Yang GY and Hu XQ: Clinical significance of neutrophil gelatinase-associated lipocalin(NGAL) expression in primary rectal cancer. BMC Cancer 9: 134, 2009.

54. Bouchet S and Bauvois B: Neutrophil gelatinase-associated lipocalin (NGAL), pro-matrix metalloproteinase-9 (pro-MMP-9) and their complex pro-MMP-9/NGAL in leukaemias. Cancers (Basel) 6: 796-812, 2014.

55. Monier F, Surla A, Guillot M and Morel F: Gelatinase isoforms in urine from bladder cancer patients. Clin Chim Acta 299: 11-23, 2000.

56. Hawinkels LJ, Zuidwijk K, Verspaget HW, de Jonge-Muller ES, van Duijn W, Ferreira V, Fontijn RD, David G, Hommes DW, Lamers CB and Sier CF: VEGF release by MMP-9 mediated heparan sulphate cleavage induces colorectal cancer angiogenesis. Eur J Cancer 44: 1904-1913, 2008.

57. Van den Steen PE, Van Aelst I, Hvidberg V, Piccard H, Fiten P, Jacobsen C, Moestrup SK, Fry S, Royle L, Wormald MR, et al: The hemopexin and O-glycosylated domains tune gelatinase B/MMP-9 bioavailability via inhibition and binding to cargo receptors. J Biol Chem 281: 18626-18637, 2006.

58. Torti SV and Torti FM: Iron and cancer: More ore to be mined. Nat Rev Cancer 13: 342-355, 2013.

59. Mertens C, Mora J, Ören B, Grein S, Winslow S, Scholich K, Weigert A, Malmström P, Forsare C, Fernö M, et al: Macrophage-derived lipocalin-2 transports iron in the tumor microenvironment. Oncoimmunology 7: e1408751, 2018.

60. Yoshiji H, Harris SR and Thorgeirsson UP: Thorgeirsson: Vascular endothelial growth factor is essential for initial but not continued in vivo growth of human breast carcinoma cells. Cancer Res 57: 3924-3928, 1997.

61. Ferreira AC, Da Mesquita S, Sousa JC, Correia-Neves M, Sousa N, Palha JA and Marques F: From the periphery to the brain: Lipocalin-2, a friend or foe? Prog Neurobiol 131: 120-136, 2015. 
62. Yang J, Bielenberg DR, Rodig SJ, Doiron R, Clifton MC, Kung AL, Strong RK, Zurakowski D and Moses MA: Lipocalin 2 promotes breast cancer progression. Proc Natl Acad Sci USA 106: 3913-3918, 2009.

63. Iannetti A, Pacifico F, Acquaviva R, Lavorgna A, Crescenzi E, Vascotto C, Tell G, Salzano AM, Scaloni A, Vuttariello E, et al: The neutrophil gelatinase-associated lipocalin (NGAL), a NF-kappaB-regulated gene, is a survival factor for thyroid neoplastic cells. Proc Natl Acad Sci USA 105: 14058-14063, 2008

64. Tong Z, Kunnumakkara AB, Wang H, Matsuo Y, Diagaradjane P, Harikumar KB, Ramachandran V, Sung B, Chakraborty A, Bresalier RS, et al: Neutrophil gelatinase-associated lipocalin: A novel suppressor of invasion and angiogenesis in pancreatic cancer. Cancer Res 68: 6100-6108, 2008
65. Le NT and Richardson DR: The role of iron in cell cycle progression and the proliferation of neoplastic cells. Biochim Biophys Acta 1603: 31-46, 2002.

c) (7) $\odot$ This work is licensed under a Creative Commons International (CC BY-NC-ND 4.0) License. 